\title{
Children's Independent Mobility: A Study of Middle Childhood Home Ranges in Two Different Socio-Physical Settings in El-Shorouk City, Egypt
}

\author{
Summer S. Hamad ${ }^{1, *}$, Yasser M. Moustafa ${ }^{2}$, Marwa H. Khalil ${ }^{2}$ \\ ${ }^{1}$ Department of Architectural Engineering, British University in Egypt, Cairo, Egypt \\ ${ }^{2}$ Department of Architectural Engineering and Environmental Design, Arab Academy for Science, \\ Technology and Maritime Transport, Cairo, Egypt
}

Received December 1, 2021; Revised January 10, 2022; Accepted February 16, 2022

\section{Cite This Paper in the following Citation Styles}

(a): [1] Summer S. Hamad, Yasser M. Moustafa, Marwa H. Khalil, "Children's Independent Mobility: A Study of Middle Childhood Home Ranges in Two Different Socio-Physical Settings in El-Shorouk City, Egypt," Environment and Ecology Research, Vol. 10, No. 2, pp. 146 - 160, 2022. DOI: 10.13189/eer.2022.100204.

(b): Summer S. Hamad, Yasser M. Moustafa, Marwa H. Khalil (2022). Children's Independent Mobility: A Study of Middle Childhood Home Ranges in Two Different Socio-Physical Settings in El-Shorouk City, Egypt. Environment and Ecology Research, 10(2), 146 - 160. DOI: 10.13189/eer.2022.100204.

Copyright $\odot 2022$ by authors, all rights reserved. Authors agree that this article remains permanently open access under the terms of the Creative Commons Attribution License 4.0 International License

\begin{abstract}
Independent mobility has a positive impact on children's cognitive, physical, and social development. Many factors affect how children utilize spaces surrounding their homes. The characteristics of both the physical and the social environments are important influencing factors. The aim of this study was to explore children's independent mobility and free exploration within their home range extent. The study investigated children's home range extent and independent mobility-related activities in two different settings selected to represent two of the most common socio-physical contexts in the new settlements being developed around Cairo. Methods of data collection included semi-structured interviews with children and parents in addition to neighborhood walk-through observations. The forty children interviewed were categorized into two age groups, 7 to 9 and 10 to 12 -year-old and included an equal number of girls and boys. The findings of the study appear to confirm the influence of gender, age, socio-economic context, and physical characteristics of the neighborhood environment on middle-aged children's independent mobility in the Egyptian context. The study suggests that land use diversity and residential density are issues that are closely related to parents' perceptions about the safety of their children around the neighborhood and need to be carefully considered in the planning of new settlements and housing projects.
\end{abstract}

Keywords Children's Independent Mobility, Middle Childhood, Children's Home Range, Egypt

\section{Introduction}

For young children, the exploration of and interaction with the environment around them is initially, to a great extent, limited to the home, the school, and perhaps some recreational institutions [1]. Their first exploration of the environment beyond the home and the school tends to be within the local neighborhood [2], [3]. Independent mobility refers to children's freedom to roam around the neighborhood either on their own or accompanied by peers [4], [5]. Benefits of independent mobility have been linked to children's physical, emotional, cognitive, and social development [4] - [7]. Children's daily experiences without adult supervision within the local neighborhood help develop their sense of place, construct their personal identity, and the process of socialization within the community [3], [8]. However, it has been observed during the past decades that, particularly for children living in urban environments, independent mobility has tended to be increasingly restricted [3], [7]. It appears to be also the case in Egypt. In older generations, children used to roam 
around their neighborhoods much more freely than today [9]. Such a restriction of children's independent mobility around their homes means a loss of play opportunities which in turn affects the child's development and wellbeing. Despite the importance of this topic to children's development, to date, very little research has investigated children's independent mobility in the Egyptian context.

Accordingly, this study aimed to investigate children's independent mobility in the Egyptian context. It relied on the concept of home range. The home range is typically defined as the home-centered spatial extent within which a child regularly moves around independently to play, socialize, or perform other activities [2], [7], [10] - [14]. In other words, it is within the home range that children's independent mobility is exercised. The extent of the home range has been suggested to be related to or affected by several factors, including, in particular, the age and gender of the child as well as the socio-economic context and physical characteristics of the built environment [2] - [4], [6], [9], [10], [15] - [23]. The specific objective of this study was then to investigate and compare the extent of children's home range in two different socio-physical contexts in Egypt. The two settings investigated were selected to represent two of the most common socio-physical contexts in the new settlements being developed around Cairo and in other places in Egypt. The study focused on middle childhood, that is children ranging between 6 and 12 years of age [24]. It is at this phase of childhood that independent mobility begins to be particularly important for the overall development of children [25]. At this age, children become more concerned about the physical environment around them [26] and are increasingly interested in exploring and understanding the neighborhood environment [10], [25]. To achieve the objective of the study, a set of research questions were formulated:

1. What is the extent of the home range (the distance that children regularly travel away from home without adult supervision)?

2. What are the activities that children perform and what are the destinations that they seek within the home range?

3. Does the extent of home range differ in relation to age and gender?

4. What are the similarities and differences in terms of children's home range between the two settings investigated?

\section{Literature Review}

\subsection{The Concept of Home Range}

The concept of home range is useful to investigate independent mobility. The child's home range is a term used to describe the world centering on the dwelling. This concept helped in defining the relationship between children and outdoor places within the vicinity of their homes such as sidewalks, backyards, neighborhood shops and vacant lots [11].

The literature offers several definitions for the term home range. These different definitions tend to agree that home range refers to the spatial extent surrounding the home where children can play and socialize regularly and independently. It encompasses places near their residential units as well as an expanding boundary leading to new places surrounding their homes [2], [7], [10] - [14].

Coates and Bussard [27] emphasized the idea that the definition of home range raises a number of questions, whether home range refers to a set of paths and nodes or an aerial unit, whether it contains only places that are frequently visited or it includes also places occasionally visited, and whether it refers only to places visited by the child alone or refers also to places visited with peers.

Some authors distinguished between different levels of home range. Moore and Young [10] mentioned three different home range levels: habitual range, frequented range, and occasional range. The habitual range represented the spaces close to home ranging from the private spaces surrounding the child's home to the public areas of local streets, playgrounds, and other waste grounds. The frequented range included those places visited regularly on weekends or during holidays. The occasional range incorporated places that are only visited under certain circumstances and not on weekly nor on daily basis. In fact, it included places that are rarely visited.

On the other hand, Hart [16] identified three different home range levels; free-range, range with permission, and range with permission when accompanied by peers or older children. The free range is the range that children are allowed to go to without having to ask or tell any of their parents. The second level is the range with permission. It includes places a child can go to after asking his/her parents. It was further explained that the term with permission means having to tell and not necessarily having to wait for permission. Moreover, it does not require the parent's permission every time. Sometimes the permission is given by an older brother or sister, usually a sister as most of the older girls are the ones who take this responsibility, in case of the absence of the mother. The word with permission also means that it can be the permission of another mother in case the child had access to one of his/her neighbors, according to the rules of this other mother. The third level is the range with permission when accompanied by other children.

\subsection{Factors Affecting the Extent of Home Range}

Although children may live in the same district, their exposure, interactions, outdoor activity opportunities, and home range extent may vary. There are different factors that affect the children's home range extent in their neighborhoods. These factors include child's age, gender 
as well as socio-economic context, physical characteristics of the built environment, and parental restrictions [2] - [4], [6], [9], [10], [15] - [23].

Age is a significant factor that has an impact on the extent of children's home range. Several studies showed that the extent of home range increases as the child gets older [2], [4], [6], [10], [15] - [19], [22]. Based on field work conducted in Coventry, Mathews [28] reported that the typical home range extent of a 6-year-old child is around $100 \mathrm{~m}$, whereas the home range extent of an 11-year-old child approaches a kilometer. He found out that a remarkable increase in the home range extent occurred around the age of eight or nine years.

Gender is another important factor that affects children's home range extent. Based on previous studies, boys have more freedom than girls do [2], [10], [16], [18] - [20]. For example, Villanueva et al. [23] argued that access to recreational destinations increases the home range extent among boys but not girls. However, some other studies stated that boys and girls had equal home range extents [6], [17]. Valentine and McKendrck [17] stated that parental restrictions were the reason that made home range extent the same for both boys and girls. Villanueva et al. [23] stated that parents who live on busy roads allow both boys and girls the same home range extents.

The home range extent is affected by the socio-economic context. The cultural background and the perception of the neighborhood affects how children use spaces surrounding their homes. For example, the availability of motorized mode of transportation may differ from socio-economic context to another which in turn affects children's home range extent [2] - [4], [9].

The built and physical environment is one of the most important factors affecting children's home range extent. This factor includes many elements such as distance to destination, density (including population, residential and street density), diversity or land use mix, walkability of the neighborhood and presence of green areas or parks. As distance to destinations such as schools and local stores increases, children's home range extent decreases [15], [21], [29]. Increased density means more homes which in turn increase sense of safety towards the neighborhood and hence increases the children's independent mobility [4]. A mixed land use neighborhood increases possibilities of children visiting the stores or shops close to their home and hence encourages children to have an independent mobility [4]. Children living in a more walkable city are associated with greater home range extent [23]. Moreover, children who lived near a park or in an apartment with an inner courtyard had more frequent visits to these places but less home range extent than those who live on a street away from such amenities [19], [23], [30]. It was argued that presence of public parks in between buildings - pocket parks - encourages young children to meet after school and increases parents' perception of their neighborhood safety [31].

The parents' perception towards their neighborhood is another important factor affecting their children's home range extent. Several studies confirmed that parents' perception of their neighborhood safety and crime rate influences the extent to which they allow their children to roam around freely in their neighborhood [9], [10], [12], [14], [16], [17], [29]. On the contrary, in their study, Lin et al. [29] stated that parents' restrictions had no impact on children's home range extent.

\section{Methodology}

\subsection{Research Design}

The study adopted a comparative research approach to investigate children's home range in two different socio-physical settings in the new city of El-Shorouk on the east of Cairo, Egypt. As previously mentioned, the two settings were selected to represent two of the most common socio-physical contexts in the new cities being developed in Egypt.

The study relied primarily on semi-structured interviews with forty children, ten girls and ten boys from each of the two settings. Additionally, observational data collected during walks in the two settings was used to complement data obtained from the interviews. Information about the two settings was obtained from different departments of El-Shorouk City Authority as well as field physical documentation recorded with photographs and annotations on base maps.

\subsection{Description of the Two Settings Selected for the Study}

EL-Shorouk is one of the new cities planned and developed on the periphery of Cairo. It was established in 1995 on an area of 16,110 acres [32]. The two settings selected for the study are two adjoining districts of the city (see Figure 1).

The first of the two selected settings, Setting A, was planned as a residential area of medium-high economic status with a density of about 100 inhabitants per acre [32]. It is composed of four-storey apartment buildings built by small private developers on plots of lands ranging in area from 600 to $1000 \mathrm{~m}^{2}$. As per the city construction regulations, the apartment buildings are built on $60 \%$ of the plot area. The large majority of the buildings feature two apartments per floor. Accordingly, most of the apartments in the district are at least $180 \mathrm{~m}^{2}$ in area. In general, the apartment buildings are organized around small public parks that are well landscaped and relatively well maintained (see Figure 2). In terms of services, the area features a small shopping mall, a grocery store, two mosques, and a public school. There is also a private sports club on the southern edge of the district.

Setting B is located immediately to the east of Setting A. 
It consists of a governmental housing project planned with a density of 250 inhabitants per acre for medium low and lower economic status residents [32]. Apartment blocks are between four and five storeys and feature apartments ranging between 70 to $135 \mathrm{~m}^{2}$ in area. Most of the planned green spaces between apartment blocks are yet to be planted. Setting B is characterized by a greater land use diversity than Setting A. It features two small shopping malls and a number of small commercial establishments located on the ground floor of some of the apartment blocks (three grocery stores, two pharmacies, a fruits and vegetables store, a stationary store, a dry cleaner, and a butcher shop). Setting B also features two mosques, two public schools, a public library, and a police station.

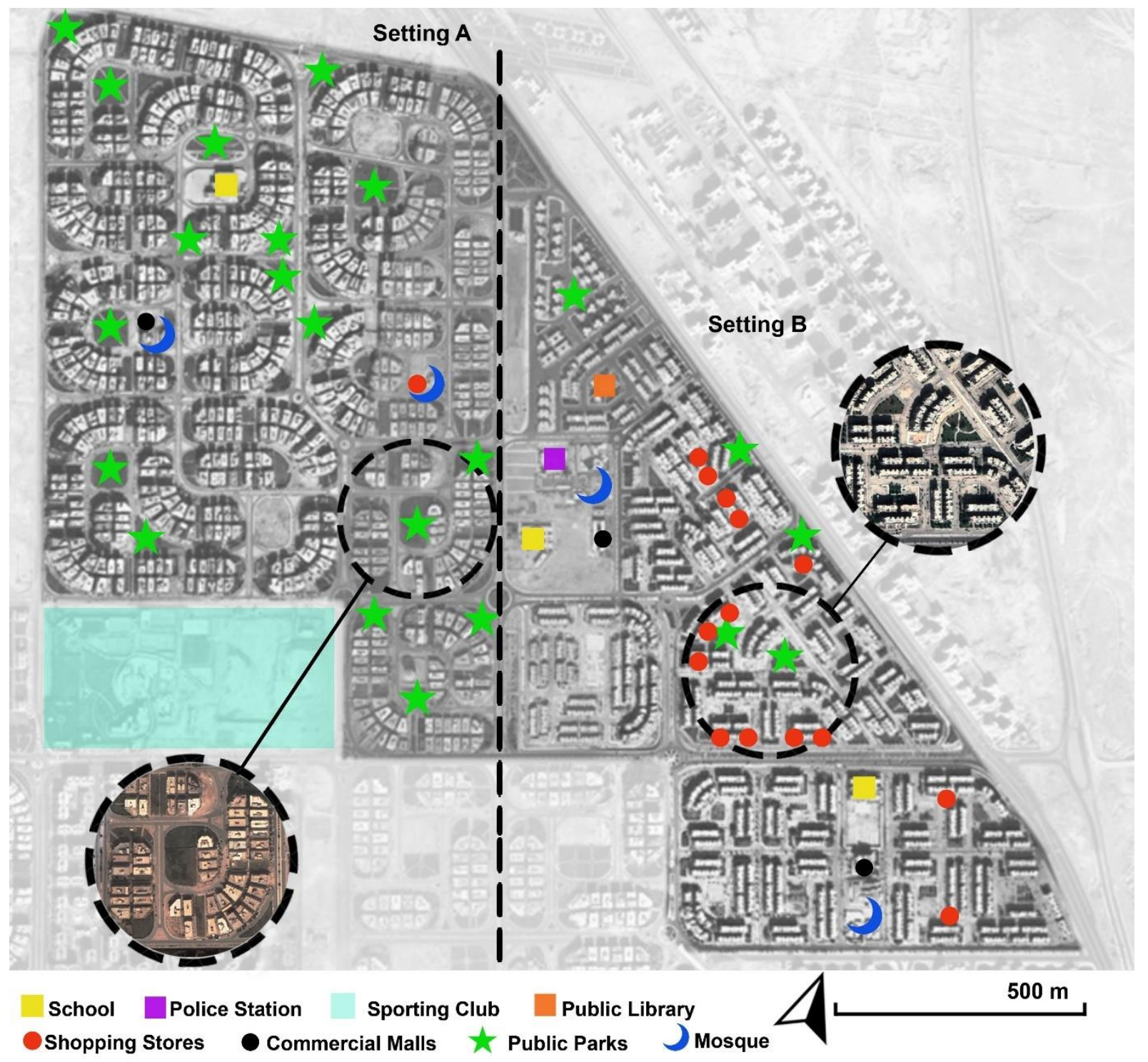

Figure 1. The two selected settings 


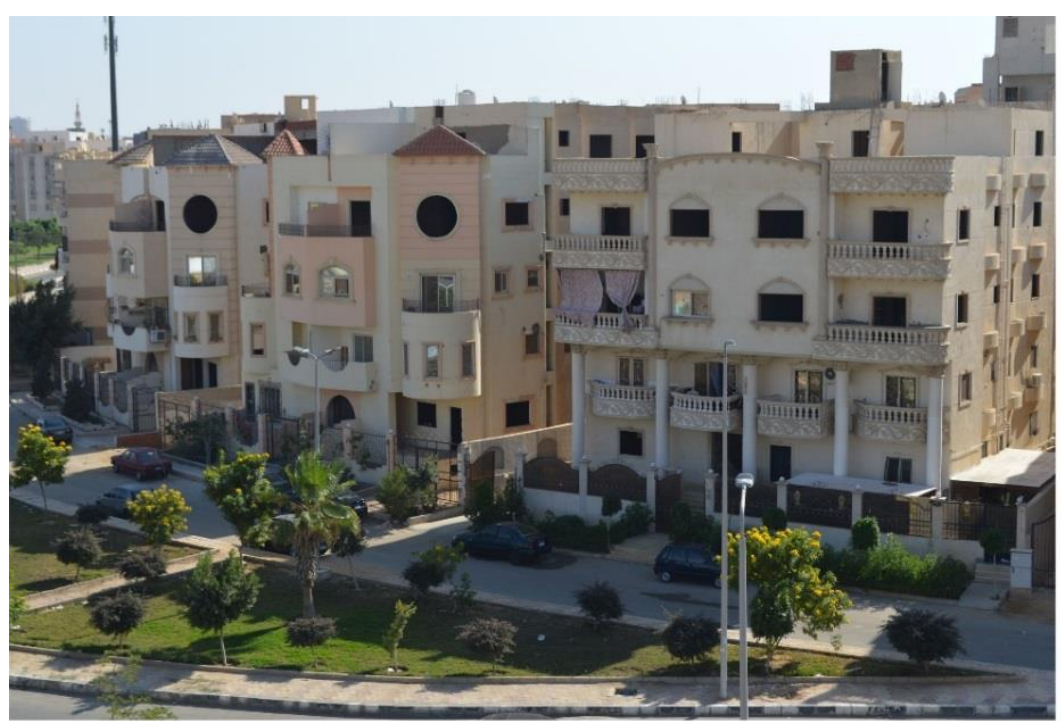

Public parks in front of apartment buildings

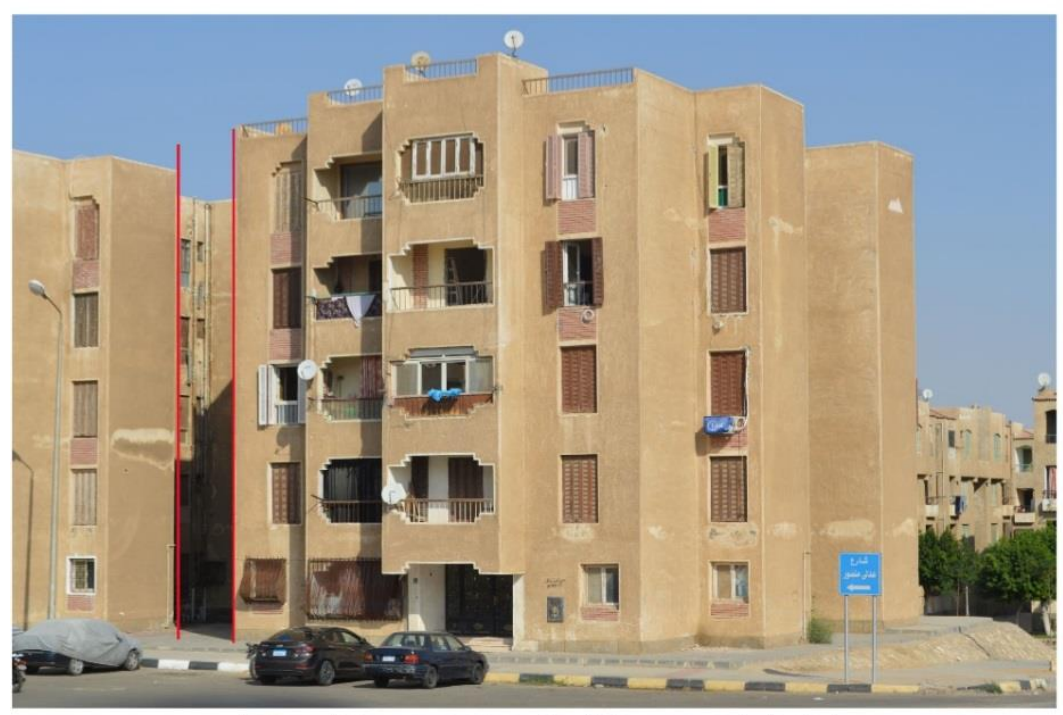

Spaces between apartment buildings are not planted

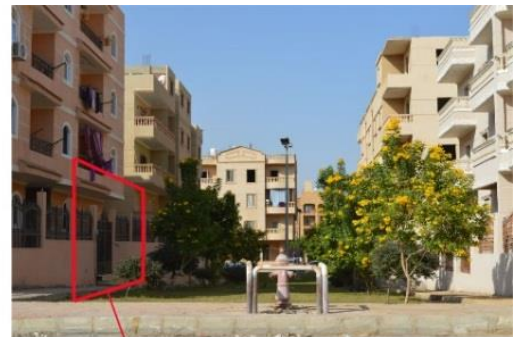

Apartment buildings entrance

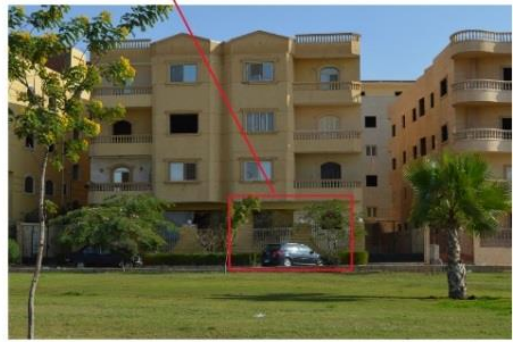

Planted spaces between apartment buildings

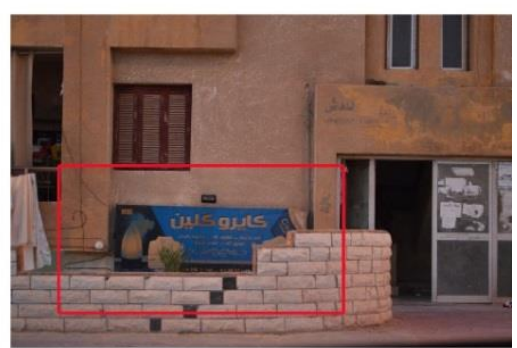

Stores on ground floor of buildings

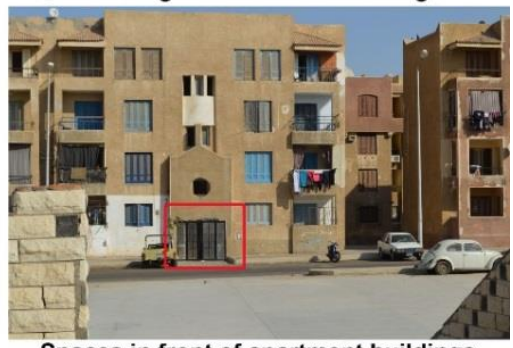

Spaces in front of apartment buildings

Figure 2. Photographs for the two selected settings - Top: Setting A, Bottom: Setting B

\subsection{Data Collection}

The study proceeded in two phases. The first phase, conducted in December 2020, was a pilot study with the aim to get acquainted with the settings and refine the data collection tools and protocol [33].

During this phase, through five field visits, the physical documentation of the two settings was completed. During these field visits, informal interviews with nine children were also conducted. These informal interviews helped refine the protocol for the semi-structured interviews conducted in the second and main phase of the study.

The second phase was conducted between January and June 2021. It involved twelve field visits to the two settings during which semi-structured interviews were conducted with forty children. The field visits were generally conducted in the late afternoon, between 4:00 and 6:00 pm. First, of course, it was judged more appropriate to approach children during daytime. But, also, during the pilot study, it was at this particular time of the day that the greatest numbers of children were observed playing outdoors and roaming about the two settings.

All the children approached for the interviews were either playing in front of their apartment buildings or were walking around in the company of at least one of the parents. This was necessary to be able to obtain parental consent for participation in the study. Parents were first explained the objectives of the study and then asked for the permission to interview their child. It should be mentioned that in many instances parents did not agree. Nevertheless, it is important to stress that for all children interviewed parental consent was obtained. In many cases, conversations with the parents were an opportunity to ask them about restrictions they may place on the independent mobility of their children.

The interviews were conducted with the help of a base 
map and an interview data recording sheet, both developed following the pilot study. The recording sheet was used to quickly note children's answers to interview questions.

In middle childhood, children can relatively easily read maps and relate them to real places [34], [35]. In addition, the use of base maps during the interview of children has been found to be very useful [36]. Children interviewed were first asked about their age. Then they were shown and briefly explained the base map and asked to locate their home on it. Most of the children could easily accomplish this task. However, some of them needed some time to do it and few even needed the help of parents, older siblings, or friends present during the interview. The children were also asked about the locations of their schools and how they go there. Following this, the interviews focused on the places the children go to or visit without adult supervision, whether they are allowed to go there on their own or need the company of older siblings, the purpose of going to these places or the activities performed there, the frequency with which these destinations are sought (daily, weekly, rarely) and how they go there (walking or biking).

To complement interview data, observational data about children's movements and outdoor play in the two settings was also collected during the field visits conducted during both the pilot study and the main phase of the study.

\subsection{Participants}

Semi-structured interviews were conducted with twenty children from each of the two settings for a total of forty interviews. The selection of the children interviewed adopted a purposive sampling approach. First, the children were selected to achieve an appropriate geographical distribution of home locations in both Setting A and Setting B. Second, the children were selected to ensure an equal distribution in terms of gender and in terms of age within each setting and across the two settings. In terms of age, two age groups were considered, 7 to 9 years and 10 to 12 years. The same age groups were used in previous research on children's home range (see for example Coates and Bussard [27]). Accordingly, the children interviewed in each of the two settings were five girls 7 to 9 years old, five boys 7 to 9 years old, five girls 10 to 12 years old, and five boys 10 to 12 years old.

\subsection{Data Analysis}

To facilitate comparative analysis between age groups, between genders, and across settings, data obtained from each of the children interviewed was categorized and tabulated. This involved in particular information about independent mobility-related activities performed and destinations sought, including how these destinations are reached (on foot or by bike) and with what frequency they are sought. For each child, the locations of the home and the different independent mobility-related destinations sought were recorded on a scaled base map. The crow's flight distance between the home and the furthest independent mobility-related destination from the home was taken as a measure of the extent of the home range of the child [10], [16]. Only destinations that the child can go to on his or her own were considered. Destinations requiring the company of older siblings were not considered. It should be noted, however, that several of the children interviewed indicated that in the company of older siblings they could go to places much further away than the places they could go to on their own. For children who reported that their independent mobility was restricted to playing right in front of their apartment buildings, the extent of the home range was considered to be $20 \mathrm{~m}$. While it's true that crow's flight distances do not reflect exact travel distances, they have been found to appropriately reflect ease of travel in previous research [12], [16], [18].

\section{Results}

This section presents the results related to the extent of home range, independent mobility-related activities performed, and destinations sought for 7- to 9-year-old and 10- to 12-year-old girls and boys from both settings $\mathrm{A}$ and B.

All of the children interviewed reported that their independent goings and comings were always with the permission or knowledge of parents. Accordingly, the home range discussed here corresponds to the "range with permission" [16].

\subsection{Girls - 7 to 9 Years Old}

For 7- to 9-year-old girls from both settings A and B, independent mobility-related destinations are strictly reached on foot. However, there were clear differences between the two settings in terms of home range extent, independent mobility-related activities performed, and destinations sought.

For three of the five girls of this age group interviewed in Setting A, independent mobility was restricted to playing right in front of the apartment building. This was the case for only one of the five girls interviewed in Setting B. In general, the estimated home range extent for girls from Setting B was much greater than girls from Setting A. In fact, the calculated average home range extent was $50 \mathrm{~m}$ for Setting A and as much as $278 \mathrm{~m}$ for Setting B (see Table $1)$.

Data obtained from 7- to 9-year-old girls also show a greater range of activity types related to independent mobility in Setting B than in Setting A. In Setting A, playing was the only activity related to independent mobility. Playing activities mainly took place in front of the apartment building and generally on a daily basis. Two of the five girls interviewed in Setting A also reported seeking, on a weekly basis, other, more distant, playing places within the neighborhood - such as nearby public 
parks up to $100 \mathrm{~m}$ away from the home (see Figures $3 \& 4$ ).

For independent mobility-related activities of 7- to 9-year-old girls in Setting B, all of the five girls interviewed indicated playing, generally on a daily basis, in front of the apartment building or in other places up to $120 \mathrm{~m}$ away from the home such as in front of friends' apartment buildings or in nearby neighborhood open spaces. Three of the girls indicated going shopping, typically on a weekly basis, for distances that ranged between 80 and $450 \mathrm{~m}$ away from the home. One of the girls mentioned going to the mosque for religion classes and another one mentioned going to pick up younger siblings. These activities involved walks of 130 and $100 \mathrm{~m}$ from the home respectively. Two of the girls reported walking to school every day on their own for up to $600 \mathrm{~m}$ way from the home (see Figures $3 \& 4$ ). Other girls also mentioned walking to school but in the company of older siblings. This is why they do not appear on the graph in Figure 3. Many of the children interviewed in Setting B (girls and boys of both age groups) go to the public schools within the neighborhood. In contrast, all of the children interviewed in Setting A go to private schools that are too far away for them to go to school on their own. They all reported being driven or bused to school.

Table 1. Home range extent measured in meters - Girls

\begin{tabular}{|c|c|c|c|c|c|c|c|c|c|c|c|c|c|}
\hline \multirow[b]{3}{*}{ Gender } & \multirow[b]{3}{*}{ Age } & \multicolumn{6}{|c|}{ Setting A } & \multicolumn{6}{|c|}{ Setting B } \\
\hline & & \multicolumn{5}{|c|}{ Participants } & \multirow{2}{*}{ Average } & \multicolumn{5}{|c|}{ Participants } & \multirow{2}{*}{ Average } \\
\hline & & 1 & 2 & 3 & 4 & 5 & & 1 & 2 & 3 & 4 & 5 & \\
\hline \multirow{2}{*}{ Girls } & $7-9$ & 20 & 90 & 100 & 20 & 20 & 50 & 20 & 70 & 550 & 600 & 150 & 278 \\
\hline & $10-12$ & 40 & 300 & 950 & 140 & 40 & 294 & 950 & 240 & 300 & 1150 & 350 & 598 \\
\hline
\end{tabular}

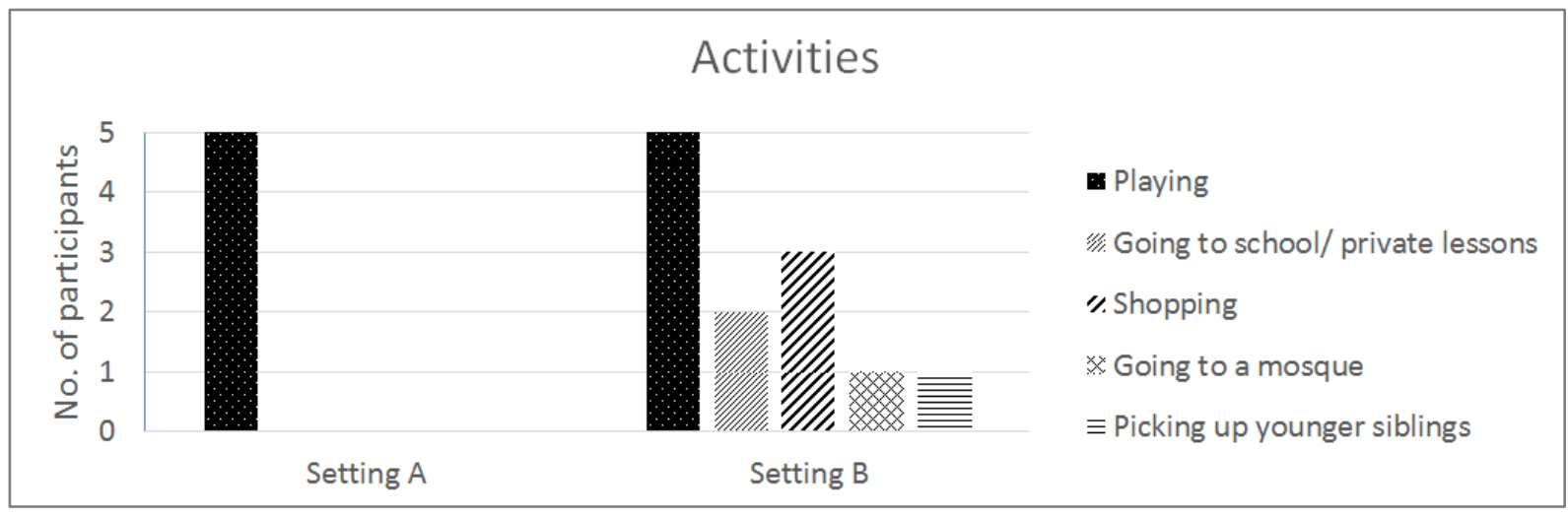

Figure 3. Independent mobility-related activities reported - Girls aged 7 to 9

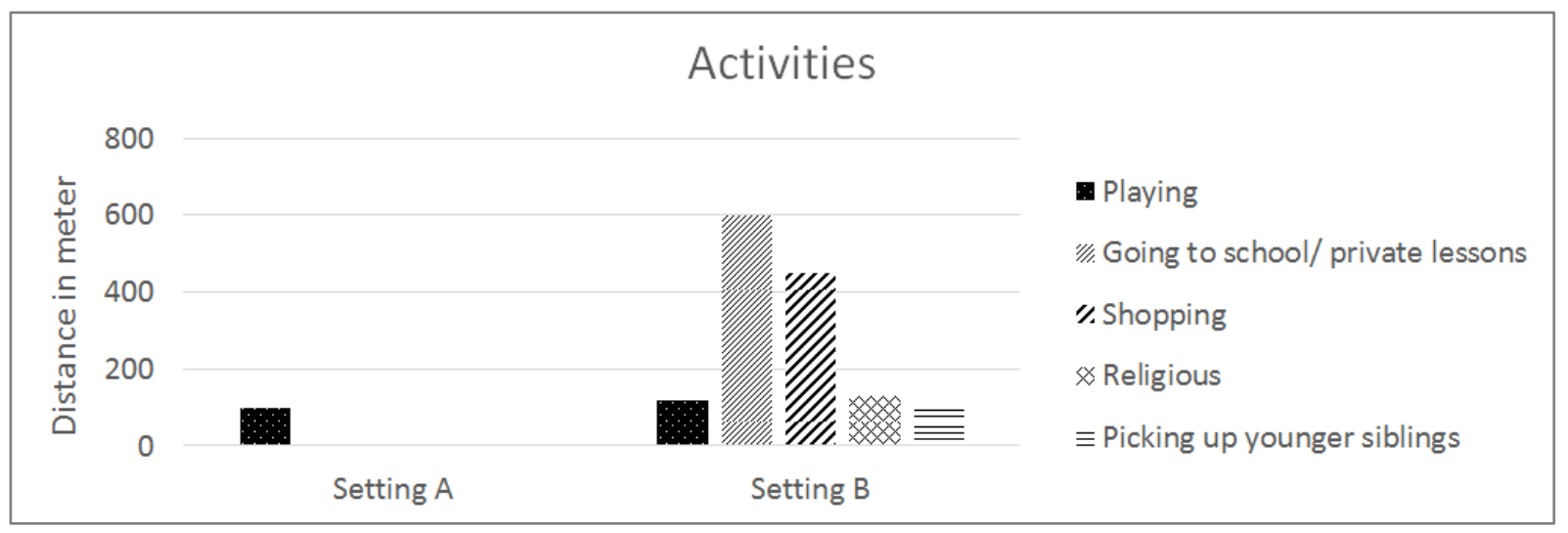

Figure 4. Maximum travel distance for independent mobility-related activities reported - Girls aged 7 to 9 


\subsection{Girls - 10 to 12 Years Old}

For 10- to 12-year-old girls of both settings, the home range extent was much greater than that of girls of the younger age group. However, for 10- to 12-year-old girls, like for 7- to 9-year-old girls, there was a clear difference in home range extent between Setting A and Setting B.

For the five 10- to 12-year-old girls interviewed in Setting A, the home range extent ranged from 40 to $950 \mathrm{~m}$, with a calculated average of $294 \mathrm{~m}$. On the other hand, for the five girls interviewed in Setting B, the home range extent ranged from 240 to $1,150 \mathrm{~m}$ with a calculated average of $598 \mathrm{~m}$ (see Table 1). For this age group, girls of Setting A indicated that they reached independent mobility-related destinations by foot or by bike. In contrast, girls of Setting B indicated that they reached independent mobility-related destinations only by foot.

Playing and going shopping were the most common independent mobility-related activities for $10-$ to 12-year-old girls of both settings. Four of the five girls interviewed in Setting A indicted playing, on a daily basis, in front of the apartment building or at other locations such as public parks up to $700 \mathrm{~m}$ away from the home. Three of the girls indicated going shopping, typically on a weekly basis, for distances up to $950 \mathrm{~m}$ away from the home. One of the girls indicated going to a friend's home in the neighborhood. One girl indicated walking the dog around the block. One girl indicated going to a private tutor in the neighborhood. And, finally, one girl indicated going to pick up a younger sibling only when her parents could not, even though the nursery is not far from the home. Some of the girls of Setting A made clear that they were only allowed to go to more distant destinations (such as shopping destinations) during the day and not after sunset.

In Setting B, all of the five 10- to 12-year-old girls interviewed indicated playing, on a daily basis, in front of the apartment building or at locations up to $1,150 \mathrm{~m}$ away from the home such as nearby streets and various neighborhood open spaces. Also, all of the five girls indicated going shopping, on a daily or weekly basis, for distances up to $960 \mathrm{~m}$ from the home. Two of the girls interviewed reported walking every day to their school in the neighborhood on their own. Finally, one of the girls indicated going to a friend's home in the neighborhood (see Figures $5 \& 6$ ).

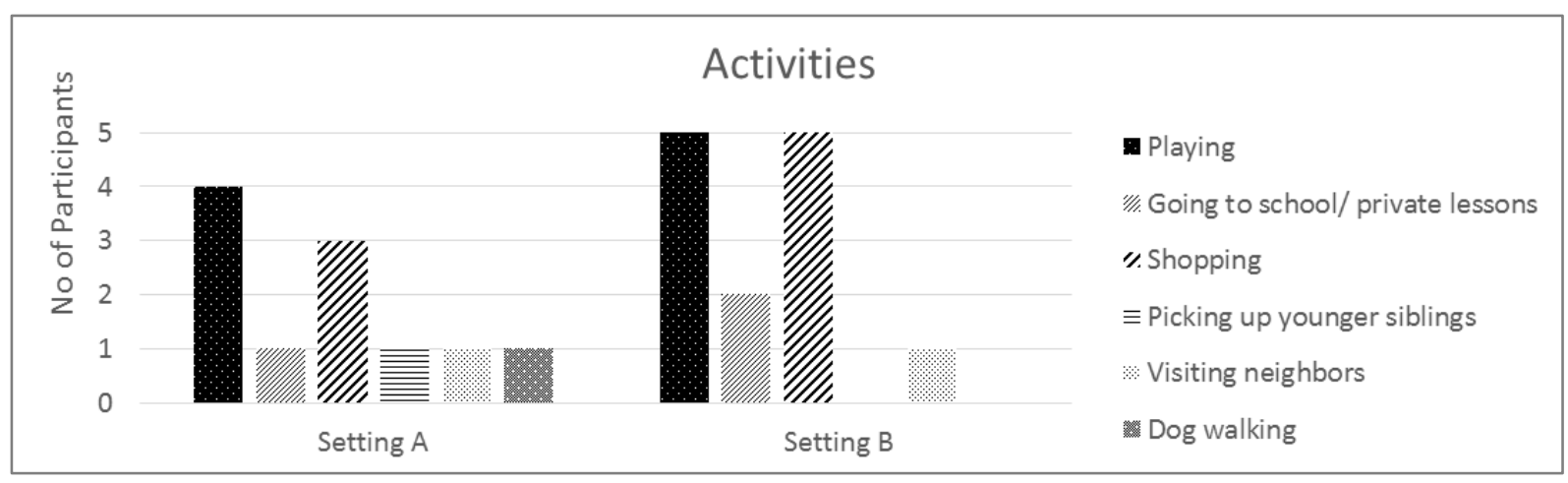

Figure 5. Independent mobility-related activities reported - Girls aged 10 to 12

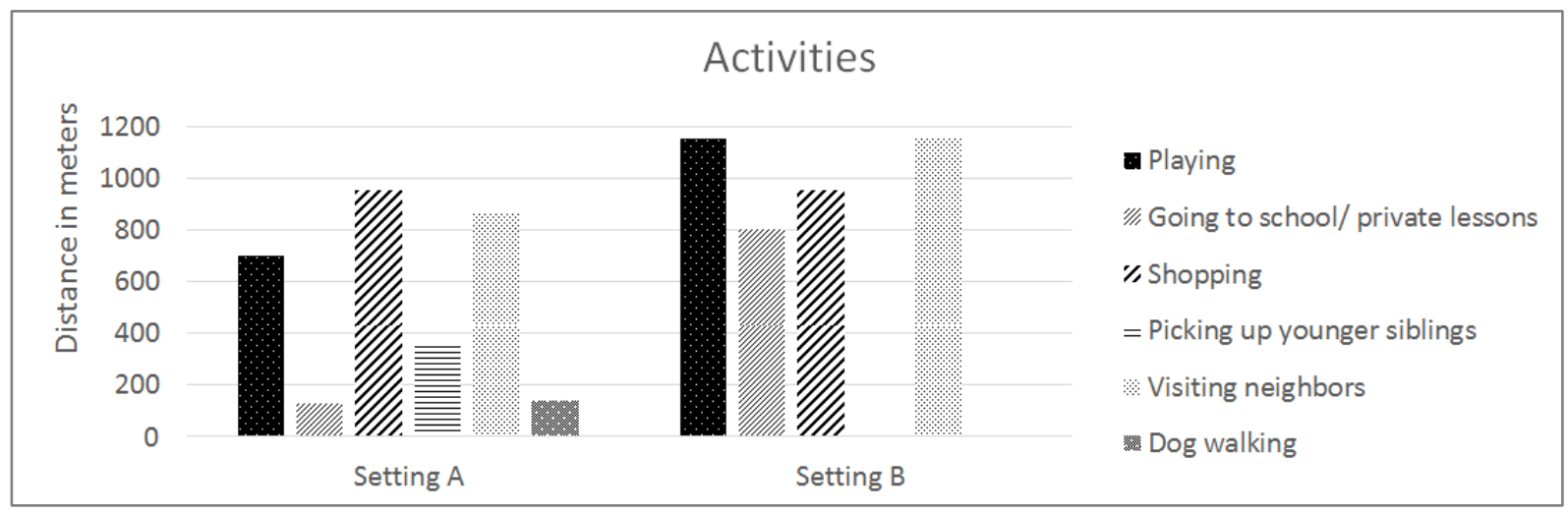

Figure 6. Maximum travel distance for independent mobility-related activities reported - Girls aged 10 to 12 
Table 2. Home range extent measured in meters- Boys

\begin{tabular}{|c|c|c|c|c|c|c|c|c|c|c|c|c|c|}
\hline \multirow[b]{3}{*}{ Gender } & \multirow[b]{3}{*}{ Age } & \multicolumn{6}{|c|}{ Setting A } & \multicolumn{6}{|c|}{ Setting B } \\
\hline & & \multicolumn{5}{|c|}{ Participants } & \multirow{2}{*}{ Average } & \multicolumn{5}{|c|}{ Participants } & \multirow{2}{*}{ Average } \\
\hline & & 1 & 2 & 3 & 4 & 5 & & 1 & 2 & 3 & 4 & 5 & \\
\hline \multirow{2}{*}{ Boys } & $7-9$ & 1200 & 20 & 595 & 1200 & 20 & 607 & 20 & 150 & 700 & 250 & 470 & 318 \\
\hline & $10-12$ & 1200 & 870 & 920 & 1280 & 980 & 1050 & 750 & 650 & 470 & 570 & 1400 & 768 \\
\hline
\end{tabular}

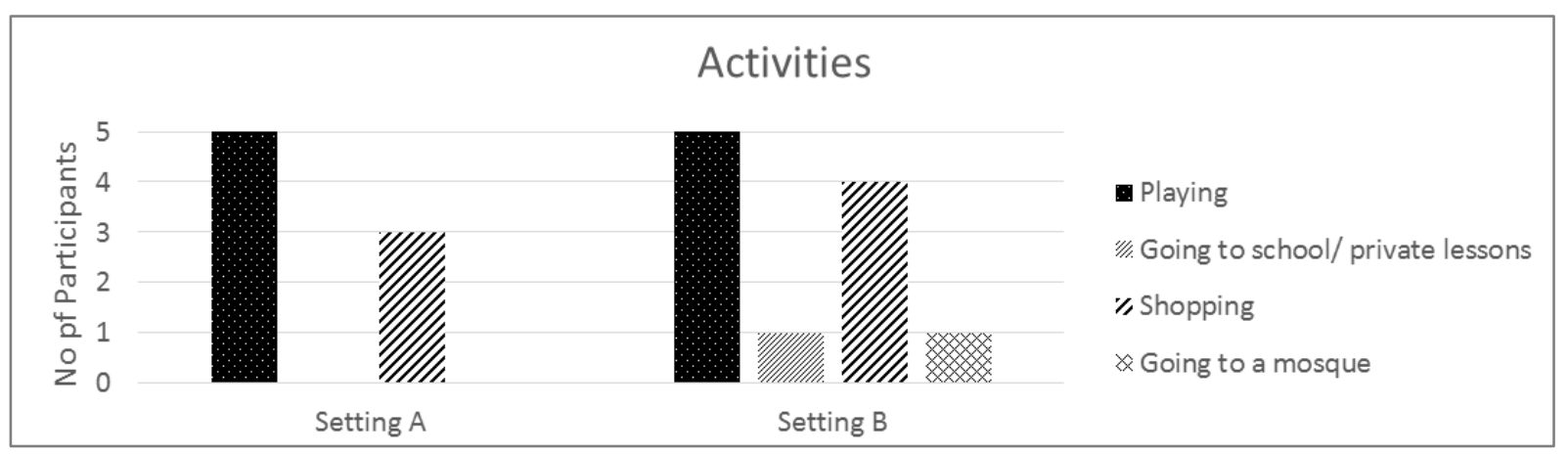

Figure 7. Independent mobility-related activities reported - Boys aged 7 to 9

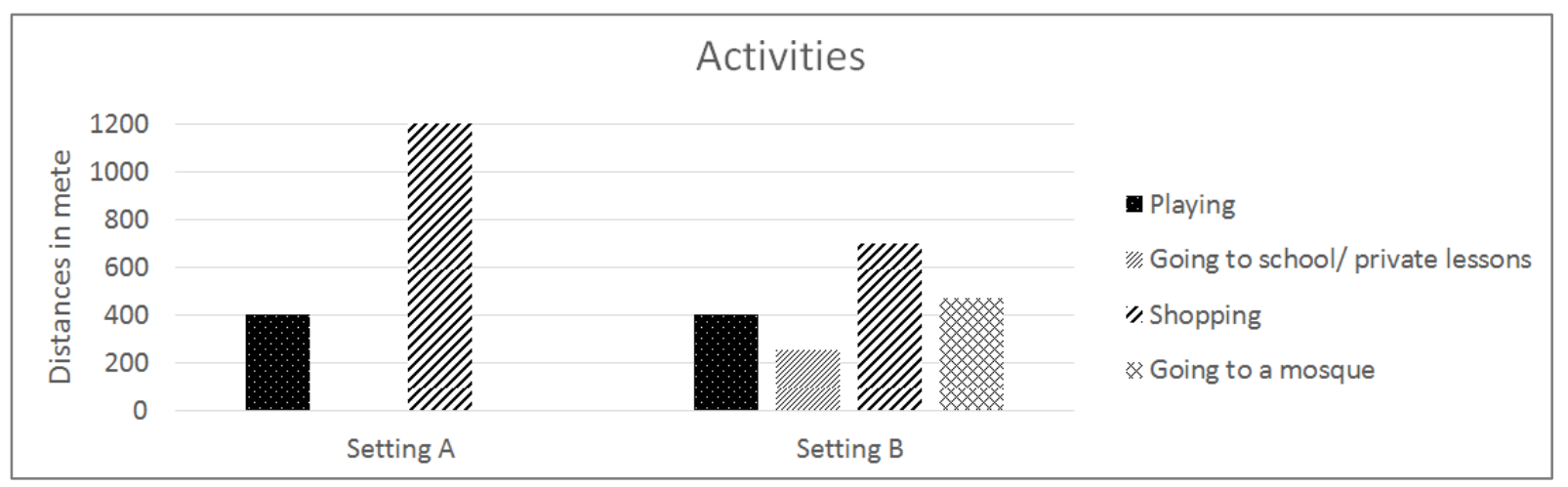

Figure 8. Maximum travel distance for independent mobility-related activities reported - Boys aged 7 to 9

\subsection{Boys - 7 to 9 Years Old}

For boys of both age groups (7 to 9 and 10 to 12 years) interviewed in the two settings $\mathrm{A}$ and $\mathrm{B}$, the calculated average home range extent was much greater than that of girls of the same age group (compare Tables $1 \& 2$ ). In fact, during the walk, through observation sessions, boys were found to be present in much greater numbers than girls on street and in open spaces of the two settings. And actually, one of the parents interviewed, parent of a daughter aged 11 and a son aged 9 , acknowledged being more restrictive about the independent mobility of his daughter compared with restrictions imposed on his son.

For girls of both age groups, the average home range extent for girls from Setting B was found to be greater than that of girls from Setting A. In contrast, for boys of both age groups, the average home range extent for boys of Setting A was calculated to be greater than that of boys of Setting B. The primary reason for this is that most of the boys interviewed in Setting A reported going shopping to the shopping malls and other commercial establishments located in Setting B, quite a distance away from their homes. This was the case for three of the five 7- to 9-year-old boys and all of the five 10- to 12-year-old boys. Only one of the ten girls interviewed in Setting A (a 10- to 12-year-old girls) reported going shopping in Setting B.

For 7- to 9-year-old boys interviewed in both settings A and $\mathrm{B}$, independent mobility-related destinations are mainly reached on foot. However, two boys from each setting indicated also using their bikes. For two boys from Setting A and only one boy from Setting B, independent mobility was restricted to playing right in front of the apartment building. But the average home range extent was calculated to be $607 \mathrm{~m}$ for the five boys of Setting A and $318 \mathrm{~m}$ for the five boys of Setting B (see Table 2).

In Setting A, all of the five 7- to 9-year-old boys interviewed indicated going to play on a daily basis in places up to from 20 to $400 \mathrm{~m}$ away from the home. These places included mainly the sidewalk right in front of the apartment building and public parks in the neighborhood. 
Three of the five boys indicated going shopping, generally on a weekly basis, to places in both Setting A and Setting B, up to $1,200 \mathrm{~m}$ away from the home (see Figures $7 \& 8$ ).

In Setting $\mathrm{B}$, playing was also an independent mobility-related activity mentioned by the five 7- to 9 -year-old boys interviewed. They indicated seeking play places on a daily basis. As mentioned above, one of them was restricted to playing right in front of the apartment building. The four other boys reported going to play in various neighborhood open spaces up to $400 \mathrm{~m}$ away from the home. Four of the five boys indicated going shopping within the neighborhood, almost on a daily basis, for distances up to $700 \mathrm{~m}$ away from the home. One of the boys indicated walking to school every day on his own for a distance of $250 \mathrm{~m}$ from his home. Another boy mentioned going to the mosque on a weekly basis for religion lessons for a distance of $470 \mathrm{~m}$ from home (see Figures $7 \& 8$ ).

\subsection{Boys - 10 to 12 Years Old}

For 10- to 12-year-old boys interviewed the extent of home range tended to be greater than that of 7- to 9 -year-old boys. The average home range extent was calculated to be $1,050 \mathrm{~m}$ for the five 10 - to 12 -year-old boys from Setting A and $768 \mathrm{~m}$ for the five 10- to 12-year-old boys for Setting B (see Table 2). In both settings, boys of this age group mainly reached independent mobility-related destinations on foot. Two of the boys from Setting A and one from Setting B mentioned also using their bikes.

In Setting A, all of the five 10- to 12-year-old boys interviewed indicated going to play on daily basis in places within the neighborhood up to $870 \mathrm{~m}$ away from the home. Two of them mentioned going to the private sporting club walking to play or meet friends or do sports. Also, all five boys reported going shopping generally on a weekly basis for a distance of up to $1,280 \mathrm{~m}$ away from the home. Four of the five boys indicated going to shopping destinations in both Setting A and Setting B. On the other hand, one of the boys explained that he could only go shopping within Setting A and was not allowed to go to Setting B even though some shopping destinations there were closer to his home. Two of the boys reported going for private lessons on a weekly basis for a distance of up to $350 \mathrm{~m}$ away from the home. And, one of the boys indicated walking to the mosque on a weekly basis for religion lessons for a distance of $350 \mathrm{~m}$ from the home (see Figures $9 \& 10$ ).

In Setting B, playing was also reported by the five 10- to 12-year-old boys interviewed as a daily independent mobility-related activity. Three of them indicated going to play in various places within the neighborhood up to $650 \mathrm{~m}$ away from the home. Two of the boys also mentioned going to play in another nearby neighborhood for distances of 750 and $1,400 \mathrm{~m}$ from their homes. All five boys indicated going shopping on a daily basis within the neighborhood for up to $600 \mathrm{~m}$ away from the home. Three of the five boys reported walking to school every day on their own for up to $380 \mathrm{~m}$ from the home. Finally, one of the 10- to 12-year-old boys interviewed in Setting B mentioned going to the mosque on a weekly basis, $470 \mathrm{~m}$ away from his home (see Figures $9 \& 10$ ).

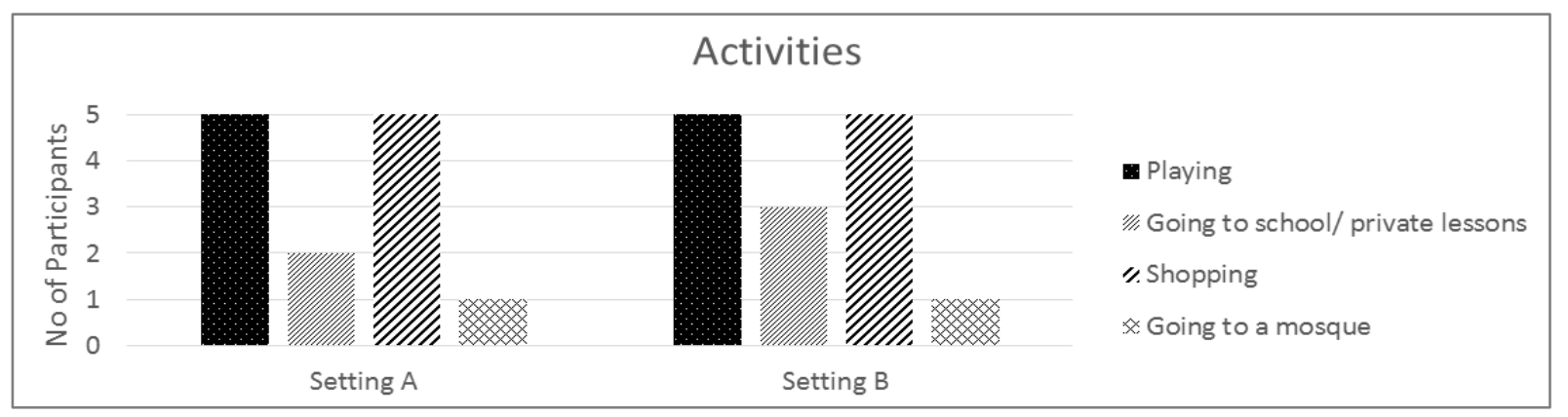

Figure 9. Independent mobility-related activities reported - Boys aged 10 to 12

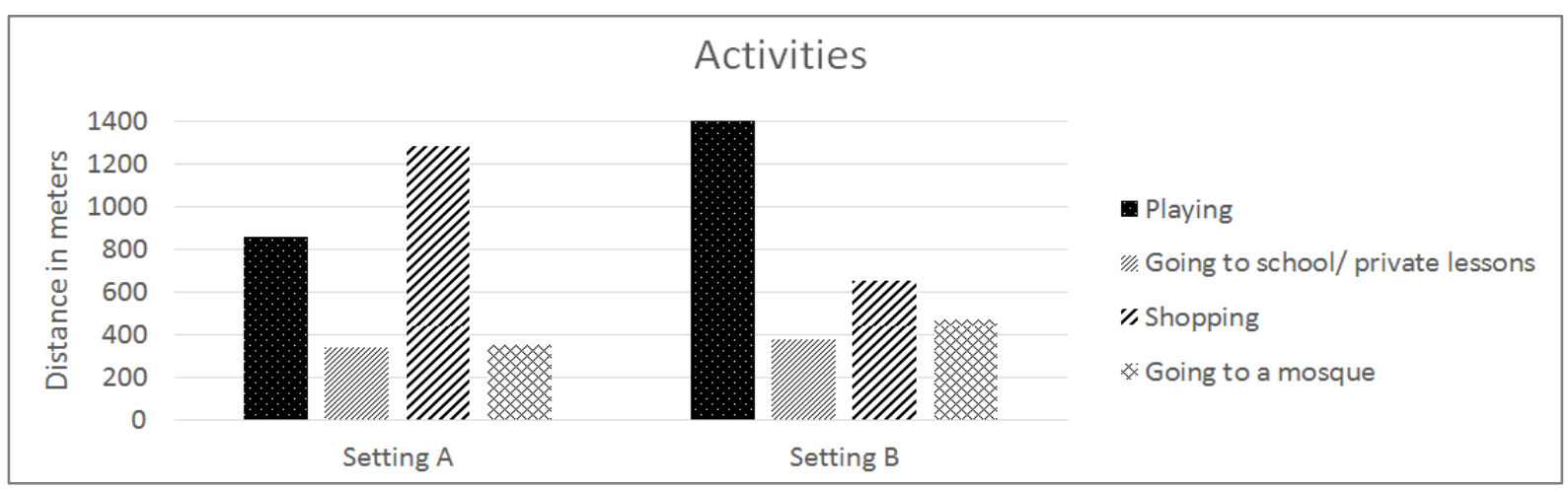

Figure 10. Maximum travel distance for independent mobility-related activities reported - Boys aged 10 to 12 


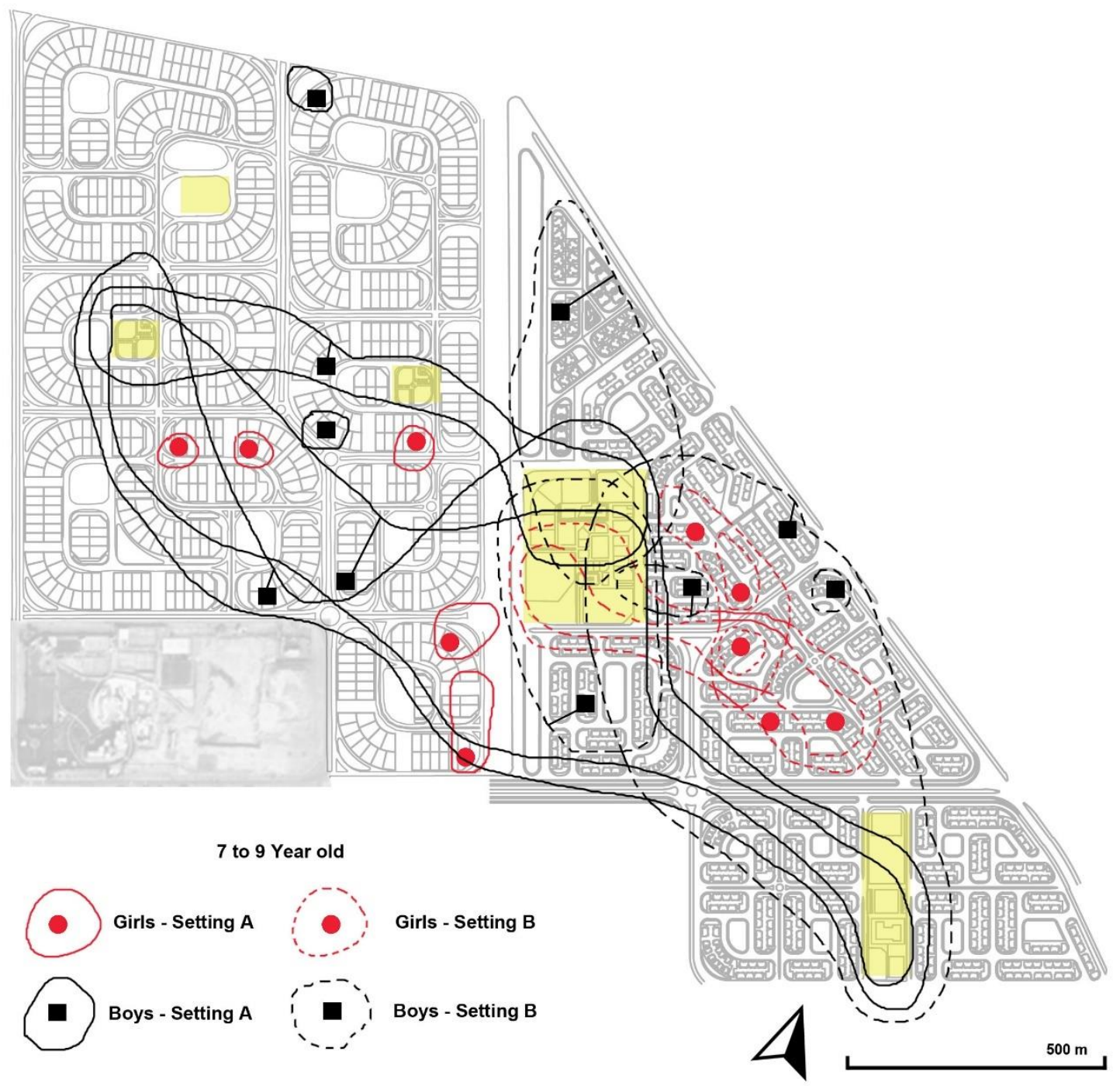

Figure 11. Home range extent for 7- to 9-year-old girls and boys 


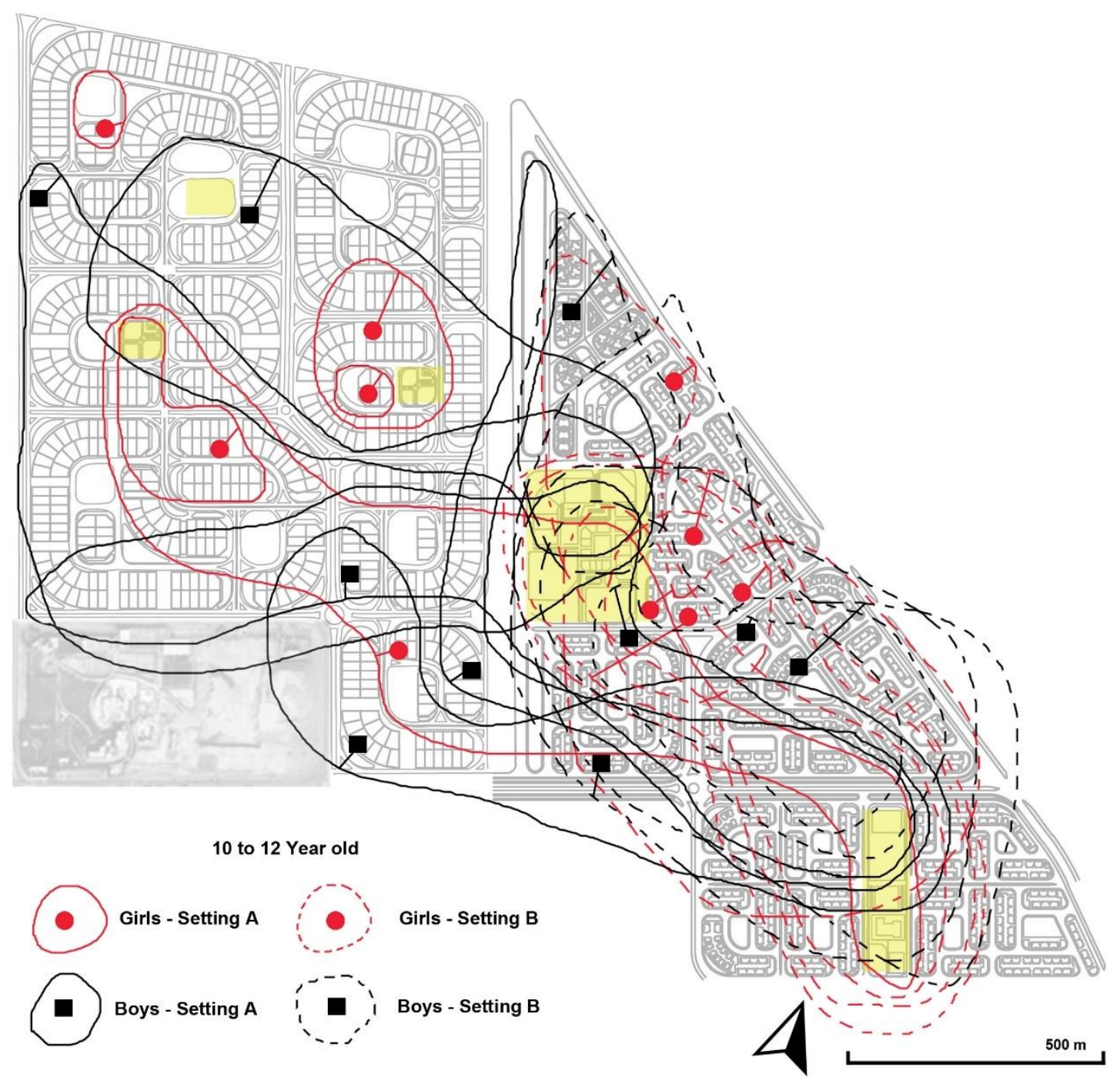

Figure 12. Home range extent for 10- to 12-year-old girls and boys

\section{Discussion}

The results of the study suggest that gender and age of the child in addition to the social context and the physical characteristics of the neighborhood environment are factors that affect children's independent mobility, particularly in terms of home range extent and independent mobility-related activities.

Gender-related differences in independent mobility among children were emphasized in previous research (see for example [2], [4], [16], [22]). In the present study, independent mobility-related activities reported were similar for girls and boys interviewed. The main activity reported was playing, followed by shopping, and then going to school (for those children who went to a school located within the neighborhood). On the other hand, there was a clear difference in home range extent between girls and boys. For the children interviewed in both settings A and $\mathrm{B}$, the home range extent of boys was much greater than that of girls of the same age group (see Figures $11 \&$ 12). This was further supported by observational data showing that boys were much more visible than girls in the streets and open spaces of the two settings. One of the main reasons behind these gender differences appears to be the differences in independent mobility restrictions imposed by parents on girls and boys. For example, among the 7- to 9-year-old children interviewed, more girls than boys reported being restricted in their independent mobility to playing right in front of the apartment building. Also, many of the girls interviewed reported not being allowed to go too far from the home after sunset, even to places they could go to during daytime. Such nighttime independent mobility restrictions were not reported by the boys interviewed. Some of the parents interviewed actually acknowledged being more restrictive about the independent mobility of daughters compared to the greater freedom allowed to sons. In their explanations, parents seemed to feel normal to be more concerned for the safety 
of daughters. It is possible to suggest that parents' restriction on the independent mobility of children is to a great extent influenced by a combination of perceived security in the neighborhood and of the socio-cultural background of parents. Nevertheless, the role played by parental restrictions in the independent mobility of children reported in this study is consistent with previous accounts in the literature (see for example [10], [17], [37]).

Age of children also appears to be an important factor affecting home range extent and independent mobility-related activities performed (see also [2], [4], [18], [28]). In the two settings investigated in this study, for both genders, the average home range extent of 7- to 9-year-old children ranged from 50 to $607 \mathrm{~m}$, whereas that of 10 - to 12 -year-old children ranged from 294 to $1,050 \mathrm{~m}$. In agreement with the findings of Mathews [28], this indicates a remarkable increase in the home range extent of 10- to 12-year-old children (see Figures 11 \& 12). Furthermore, seven of the twenty 7- to 9-year-old children interviewed reported that their independent mobility was restricted to playing in front of their apartment buildings, whereas none of the 10- to 12-year-old children interviewed reported similar restrictions. On the contrary, most of 10- to 12-year-old children reported a wider range of activity types performed within their home range extent and in many cases, they sought destinations further away from the home to perform such activities (see Figures $11 \& 12$ ). As for parental restrictions, some of the interviewed parents reported that they allow older children to roam more freely in their neighborhood. They believe that older children have a better sense of orientation and are generally more responsible and independent (see also [12], [14], [17]).

The two settings investigated were selected to represent two different socio-economic contexts. The differences observed between the two settings strongly suggest that the socio-economic context is an important factor affecting the independent mobility of children (see also [2] - [4], [9]). One of the differences noted between the two settings relates to the use of bikes. In Setting A, both boys and girls reported biking to some independent mobility-related destinations. On the other hand, in Setting B only boys reported using bikes. All of the girls interviewed in Setting $\mathrm{B}$ indicated that they do not use or even own a bike. This was also confirmed by observational data. It appears that according to the cultural norms in Setting B, the use of bikes is not really appropriate for girls. Another issue is clearly linked to the socio-economic differences between the two settings. Many of the children interviewed in Setting B reported going to the public schools located within the neighborhood. Most of them indicated walking to school every day. In contrast, all of the children interviewed in Setting A reported going to private schools typically located far beyond the boundaries of their neighborhood and that they were driven or bused to school. In addition, many of the children of Setting $\mathrm{A}$ indicated that they went to private clubs for recreational and sports activities. Two boys reported walking to the private club on the edge of Setting A (see Figure 11). But, most of the children indicated that they were typically driven by their parents to clubs quite distant from the neighborhood. This reliance on private schools and private clubs, which children can only access if driven there, seems to negatively affect the independent mobility of children of Setting A and to a large extent reduce opportunities for free exploration within the neighborhood. Setting A and Setting $\mathrm{B}$ are two adjoining districts simply separated by a moderate traffic street. However, the difference between the two settings in terms of socio-economic context seems to create some sort of barrier between them. Most of the boys interviewed in Setting A indicated that they were allowed to go to Setting B. But, only one of the girls of Setting A reported that she could go shopping in Setting B. All of the nine other girls clearly indicated that they were not allowed to cross into Setting B. Interestingly, none of the children interviewed in Setting B reported going to Setting A (see Figures $11 \&$ 12). Several of them explained that they were not allowed to. The mother of a girl of Setting B explicitly mentioned that she did not allow her daughter to cross what she perceived to be a social boundary between the two settings.

The two settings investigated were also selected for their differences in physical characteristics of the environment. As emphasized in the literature (see for example [3], [4]), the results of the study seem to show that characteristics of the built environment affect children's independent mobility and home range extent. The two settings differ particularly in terms of land use diversity, with Setting B characterized by a much greater land use diversity than Setting A. In particular, the presence of a much greater number of commercial establishments in Setting B than in Setting A appeared to be an important reason behind the observed differences in home range extent between the children of the two settings (see Figures $11 \& 12$ ). Going shopping was one of the main independent mobility-related activities reported by the children interviewed. The home range extent of boys from Setting $\mathrm{A}$ was found to be greater than that of boys from Setting B primarily because they usually went to Setting B for their shopping activities. While boys of Setting A were generally allowed to go to Setting B, the independent mobility of girls of Setting A was much more restricted and nine of the ten girls interviewed were not allowed to go to Setting B. As a result of both the lack of shopping destinations in Setting A and parental restrictions on girls' independent mobility, much fewer of the girls of Setting A reported going shopping as an independent mobility-related activity than girls of Setting B. In fact, none of the 7- to 9-year-old girls interviewed in Setting A reported going shopping on their own. The literature suggests that as the distance to potential independent mobility-related destinations increases, the home range extent of children tends to decrease as these destinations become less accessible to them (see [15], [21], [29]). In this study, results for girls and some of the boys are consistent with this (see Figures $11 \& 12$ ). Parental 
restrictions on the independent mobility of their children are mainly explained by issues of perceived security. According to parents from Setting A interviewed, concerns for the safety of their children were particularly related to the very low presence on the street in their neighborhood. In contrast, the higher residential density and land use diversity in Setting B contributed to a much greater presence in the streets of the neighborhood and consequently helped create an environment perceived as safer for the independent mobility of children (see also [3], [4], [38]). Parents of Setting B interviewed actually expressed much less safety concerns about the free movement of their children within the neighborhood. Differences in safety concerns between the two settings were particularly significant for girls. As confirmed by observational data, the number of girls seen moving around in Setting B was much greater than in Setting A.

\section{Conclusion}

The objective of this study was to investigate children's independent mobility in two different socio-physical settings in El-Shorouk city, Cairo, Egypt. The study seems to confirm the influence of gender, age, socio-economic context, and physical characteristics of the environment on middle-aged children's independent mobility in the Egyptian context. It highlights how such factors affect the home range extent and the independent mobility-related activities. In addition, the parents' perception about the safety of their neighborhood was found to be another important factor influencing children's independent mobility.

This study provides some guidance for the future planning of new settlements and housing projects. Particularly, findings suggest that land use diversity and residential density are issues that are closely related to parents' perceptions about the safety of their children around the neighborhood. Accordingly, these issues need to be carefully considered for the design of environments that would encourage greater home range extent and would promote the proper development of children.

As for the limitations of this study, it should be emphasized that the number of children interviewed was relatively low. This was related to the difficulty of approaching children, and girls in particular, as well as the difficulty of obtaining permission from parents. In many instances, parents refused the participation of their children in the study. The findings of the present study could certainly benefit from confirmation from other studies. Future research could also extend the work presented here by investigating children's independent mobility in other socio-economic contexts and environments with different physical characteristics both in Egypt and in other countries.

\section{Acknowledgments}

The authors would like to thank all the involved children and their parents for their time and willingness to participate in this study.

\section{REFERENCES}

[1] K. Rasmussen, "Places for Children - Children's Places," Childhood, vol. 11, no. 2, pp. 155-173, May 2004, doi: 10.1177/0907568204043053.

[2] A. Rapoport, "The Home Range of the Child," Athens Cent. Ekistics, vol. 45, no. 272, p. 378, 1978.

[3] K. Witten and P. Carroll, “Children's Neighborhoods: Places of Play or Spaces of Fear?," in Space, Place and Environment, K. Nairn, P. Kraftl, and T. Skelton, Eds. Singapore: Springer Singapore, 2015, pp. 1-20. doi: 10.1007/978-981-4585-90-3_25-1.

[4] N. A. Riazi and G. Faulkner, "Children's Independent Mobility," in Children's Active Transportation, R. Larouche, Ed. Elsevier, 2018, pp. 77-91. doi: 10.1016/B978-0-12-811931-0.00005-3.

[5] J. Vlaar, M. Brussoni, I. Janssen, and L. C. Mâsse, "Roaming the neighbourhood: influences of independent mobility parenting practices and parental perceived environment on children's territorial range," Int. J. Environ. Res. Public. Health, vol. 16, no. 17, p. 3129, Aug. 2019, doi: 10.3390/ijerph16173129.

[6] A. Carver, B. Watson, B. Shaw, and M. Hillman, "A Comparison Study of Children's Independent Mobility in England and Australia," Child. Geogr., vol. 11, no. 4, pp. 461-475, Nov. 2013, doi: 10.1080/14733285.2013.812303.

[7] P. Tranter, "Children's Play in Their Local Neighborhoods: Rediscovering The Value of Residential Streets," in Play, Recreation, Health and Well Being, B. Evans, J. Horton, and T. Skelton, Eds. Singapore: Springer Singapore, 2015, pp. 1-26. doi: 10.1007/978-981-4585-96-5_37-1.

[8] C. Spencer and H. Woolley, "Children and the City: A Summary of Recent Environmental Psychology Research," Child Care Health Dev., vol. 26, no. 3, pp. 181-198, May 2000, doi: 10.1046/j.1365-2214.2000.00125.x.

[9] N. Darwish, H. Gabr, and D. Shehayeb, "Where Do Cairene Children Walk to Primary School?," Procedia Environ. Sci., vol. 34, pp. 411-422, 2016, doi: 10.1016/j.proenv.2016.04. 036.

[10] R. Moore and D. Young, "Childhood Outdoors: Toward a Social Ecology of the Landscape," in Children and the Environment, 1st ed., vol. 3, I. Altman and J. F. Wohlwill, Eds. New York: Plenum Press, 1978, pp. 83-127.

[11] S. Gaster, "Rethinking the Children's Home Range Concept," Archit. Behav., vol. 11, no. 1, pp. 35-42, 1995.

[12] E. H. Cornell and D. Heth, "Home Range and the Development of Children's Way Finding," in Advances in Child Development and Behavior, R. Kail, Ed. Canada: Elsevier, 2006, pp. 173-206. 
[13] A. Abdel-Hadi, E. El-Nachar, and H. Safieldin, "Resdients' Perception of Home Range in Cairo," Open House Int., vol. 36, no. 2, pp. 59-69, 2011, doi: 10.1108/OHI-02-2011-B0007.

[14] J. C. Spilsbury, J. E. Korbin, and C. J. Coulton, "Mapping Children's Neighborhood Perceptions: Implications for Child Indicators," Child Indic. Res., vol. 2, no. 2, pp. 111131, Jun. 2009, doi: 10.1007/s12187-009-9032-z.

[15] A. Fyhri and R. Hjorthol, "Children's Independent Mobility to School, Friends and Leisure Activities," J. Transp. Geogr., vol. 17, no. 5, pp. 377-384, Sep. 2009, doi: 10.1016/j.jtrangeo.2008.10.010.

[16] R. A. Hart, Children's Experience of Place. New York: Irvington Publishers: distributed by Halsted Press, 1979.

[17] I. Janssen, T. Ferrao, and N. King, "Individual, Family, and Neighborhood Correlates of Independent Mobility among 7 to 11-year-olds," Prev. Med. Rep., vol. 3, pp. 98-102, Jun. 2016, doi: 10.1016/j.pmedr.2015.12.008.

[18] M. H. Matthews, "Gender, Home Range and Environmental Cognition,” R. Geogr. Soc., vol. 12, no. 1, pp. 43-56, 1987.

[19] M. Prezza, S. Pilloni, C. Morabito, C. Sersante, F. R. Alparone, and M. V. Giuliani, "The Influence of Psychosocial and Environmental Factors on Children's Independent Mobility and Relationship to Peer Frequentation," J. Community Appl. Soc. Psychol., vol. 11, no. 6, pp. 435-450, Nov. 2001, doi: 10.1002/casp.643.

[20] M. A. Tindal, The Home Range of Black Elementary School Children: An Exploratory Study in the Measurement and Comparison of Home Range. United States: Environmental Research Group, 1971.

[21] G. Valentine and J. McKendrck, "Children's Outdoor Play: Exploring Parental Concerns about Children's Safety and the Changing Nature of Childhood," Geoforum, vol. 28, no. 2, pp. 219-235, May 1997, doi: 10.1016/S0016-7185(97)0 0010-9.

[22] J. Veitch, J. Salmon, and K. Ball, "Children's Active Free Play in Local Neighborhoods: A Behavioral Mapping Study," Health Educ. Res., vol. 23, no. 5, pp. 870-879, Nov. 2007, doi: 10.1093/her/cym074.

[23] K. Villanueva et al., "Where Do Children Travel to and What Local Opportunities Are Available? The Relationship Between Neighborhood Destinations and Children's Independent Mobility," Environ. Behav., vol. 45, no. 6, pp. 679-705, Aug. 2013, doi: 10.1177/0013916512440705.

[24] E. Hoff, "The Creative World of Middle Childhood: Creativity, Imagination, Self-Image from Qualitative and Quantitative Perspectives," Doctoral Disseration, Lund University, Sweden, 2003.

[25] W. A. Collins, Development during middle childhood: The years from six to twelve. United States: National Academies Press, 1984.
[26] L. Chawla, "Childhood Place Attachments," in Place Attachment, I. Altman and S. M. Low, Eds. New York: Plenum Press, 1992, pp. 63-86.

[27] G. Coates and E. Bussard, "The Ecology of Children's out-of-house Activities in a Moderate Density Housing Development," EDRA 5 Proc. 21, pp. 131-142, 1974.

[28] M. H. Matthews, Making Sense of Place: Children's Understanding of Large-Scale Environments. Hemel Hempstead, Hertfordshire: Lanham, Md: Harvester Wheatsheaf; Barnes \& Noble, 1992.

[29] E. Lin et al., "Social and Built-Environment Factors Related to Children's Independent Mobility: The Importance of Neighbourhood Cohesion and Connectedness," Health Place, vol. 46, pp. 107-113, Jul. 2017, doi: 10.1016/j.healthplace.2017.05.002.

[30] H. E. Christian et al., "The Effect of the Social and Physical Environment on Children's Independent Mobility to Neighborhood Destinations," J. Phys. Act. Health, vol. 12, no. s1, pp. S84-S93, Jan. 2015, doi: 10.1123/jpah.2014-02 71.

[31] M. Hamdy and R. Plaku, "Pocket Parks: Urban Living Rooms for Urban Regeneration," Civ. Eng. Archit., vol. 9, no. 3, pp. 747-759, May 2021, doi: 10.13189/cea.2021.090316.

[32] New Urban Communities Authority, "About New Settlements/ EL Shorouk," newcities.gov, 2017. http://www.newcities.gov.eg/know_cities/shrouk/default.a spx (accessed Feb. 14, 2021).

[33] L. N. Groat and D. Wang, Architectural Research Methods, Second Edition. United States: Wiley, 2013.

[34] S. El-Husseiny, L. Sherif, and M. Khalil, "Exploration and Manipulation in Children's Play Spaces," in ARCHDESIGN "16- Third International Architectural Design Conference on Design and Nature, Istanbul, Turkey, 2016, pp. 531-540.

[35] P. Wiegand, Learning and Teaching with Maps. London; New York: Routledge, 2006.

[36] V. Morrow, "Using Qualitative Methods to Elicit Young People's Perspectives on their Environments: Some Ideas for Community Health Initiatives," Health Educ. Res., vol. 16, no. 3, pp. 255-268, Jun. 2001, doi: 10.1093/her/16.3.255.

[37] S. Schoeppe, M. J. Duncan, H. M. Badland, A. L. Rebar, and C. Vandelanotte, "Too far from home? Adult attitudes on children's independent mobility range," Child. Geogr., vol. 14, no. 4, pp. 482-489, Jul. 2016, doi: $10.1080 / 14733285.2015 .1116685$.

[38] Z. Sami and M. E. E. Dincer, "Study of Physical, Social and Functional Structures in Bagdat Street (Istanbul) as Public Space," Civ. Eng. Archit., vol. 8, no. 3, pp. 224-236, 2020, doi: 10.13189/cea.2020.080305. 